\title{
Design and Analysis of Double Excited 3-Degree-of-Freedom Motor for Robots
}

\author{
Byung-Il Kwon ${ }^{\dagger}$ and Young-Boong Kim*
}

\begin{abstract}
This paper presents a double excited three degree-of-freedom (3DOF) motor. The proposed 3DOF motor is designed with a laminated structure, making it easy to manufacture. In addition, it has windings on the stator and rotor, and does not require an expensive permanent magnet. We explain the structure, principle of motion, and design of the proposed motor, and perform an analysis of the static characteristics using the two- and threedimensional finite element methods (3D FEM). The feasibility of 3D FEM analysis is confirmed by comparing the 3D FEM analysis and experimental results for the rolling and pitching motion. We also confirm the occurrence of holding torque in every motion.
\end{abstract}

Keywords: 3DOF, Laminated structure, Double excited, 3D FEM

\section{Introduction}

To satisfy the increasing demand for robots that are able to perform increasingly sophisticated free motions in less structured environments, multi degree-of-freedom (DOF) motion is required. This parameter must consider manipulators, as well as robots, security cameras, plasma devices, and laser cutting machines [1].

In the present study, we design and propose a novel laminated-structure double excited 3DOF motor. The proposed 3DOF motor presents a more cost-effective double excited method rather than using a conventional permanent magnet. Moreover, both stator and rotor are of laminated structure, thereby improving manufacturing efficiency. To determine the holding torque of the proposed motor, the static torque of each motion is analyzed by three-dimensional finite element method (3D FEM). An experiment on a prototype is also carried out.

\section{Structure of the double excited 3DOF motor}

Fig. 1 shows the structure of the proposed 3DOF motor, which is composed of a stator, a rotor, and a $3 \mathrm{DOF}$ shaft.

The proposed motor is of double excited type, in which the stator and rotor has coils. For manufacturing convenience, the stator and rotor are designed with laminated structures.

Fig. 2(a) shows the stator structure and the winding circuit. The stator has an arrangement of 12 cores at $30^{\circ}$ intervals in the direction of the circumference. One phase

$\dagger$ Corresponding Author: Dept. of Electrical Control and Instrumentation Engineering, Hanyang University, Korea. (bikwon@hanyang.ac.kr)

* Dept. of Electrical Control and Instrumentation Engineering, Hanyang University, Korea. (dach12@naver.com)

Received: March 24, 2010; Accepted: April 7, 2011 consists of four cores, totaling three phases. The core is a C-type laminated structure [Fig. 2(b)]; one core has two teeth, and each tooth has one coil. The circuit diagram of the stator winding is shown in Fig. 2(c). Three phases are excited using three switches.

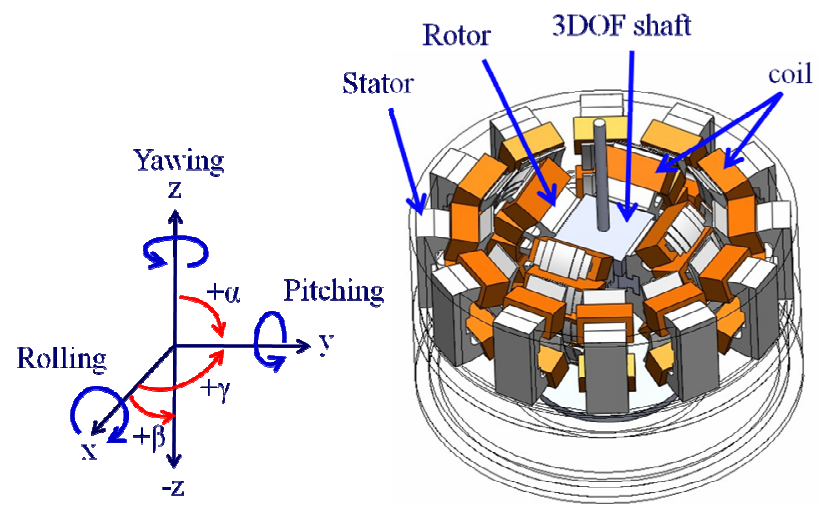

Fig. 1. Structure of the proposed double excited 3DOF motor.

Fig. 3(a) shows the structure of the rotor, which is composed of the rolling and pitching poles of the same structure. The driving circuits are also the same. Each pole consists of the two cores laminated as shown in Fig. 3(b); each core has five teeth, and each tooth has one coil. Therefore, each pole has a total of 10 coils; two diagonally located coils compose one phase, making up a total of five phases. The circuit of the rotor should be able to apply positive and negative currents. The circuit diagram of the rotor is shown in Fig. 3(c). If the circuit is switched on Q2 and Q8, the current flows in the positive direction through the slip ring on phase B. If the circuit is switched on Q3 and Q7, the current flows in the negative direction through 
the slip ring on phase $\mathrm{B}$. The rotor cores are connected to the 3DOF shaft located inside the rotor. Fig. 4 shows the design of the structure of the 3DOF shaft. The 3DOF shaft can rotate at three directional motions. In addition, a universal bearing is installed at the center of the shaft core to minimize the rotational friction.

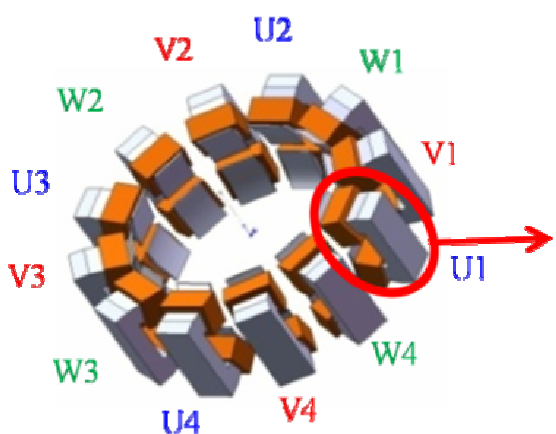

(a)

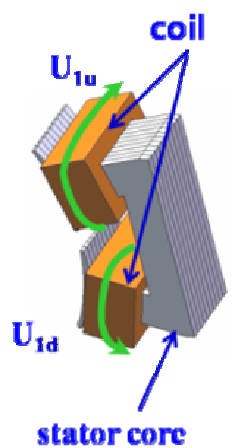

(b)

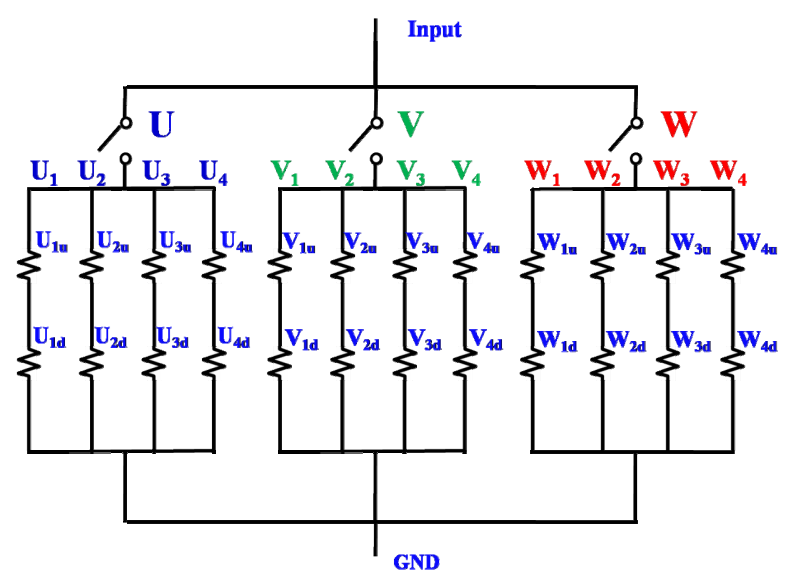

(c)
Fig. 2. Stator structure and winding circuit diagram: (a) stator structure; (b) stator core structure; (c) circuit diagram of stator winding.

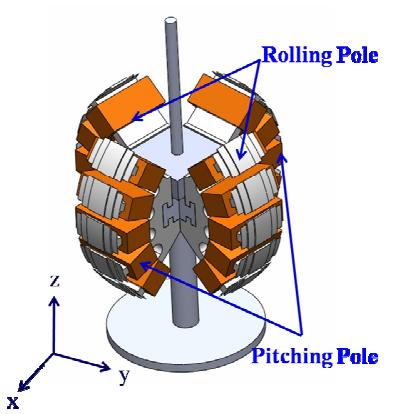

(a)

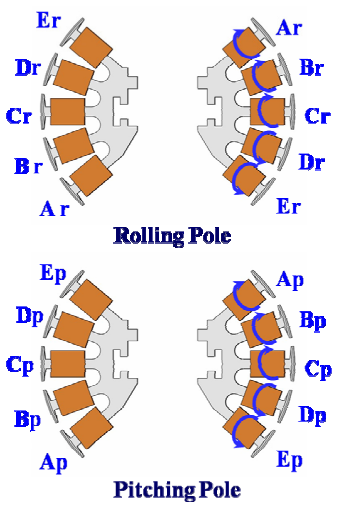

(b)

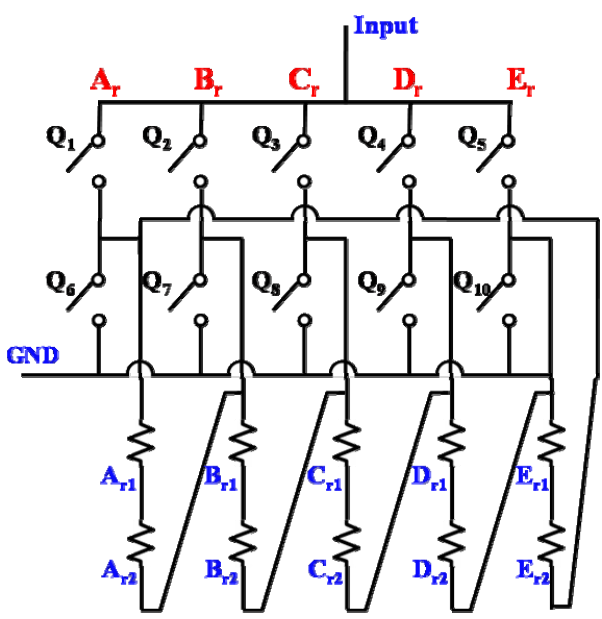

(c)

Fig. 3. Rotor structure and winding circuit diagram: (a) rotor structure; (b) rotor core structure; (c) circuit diagram of rotor winding.
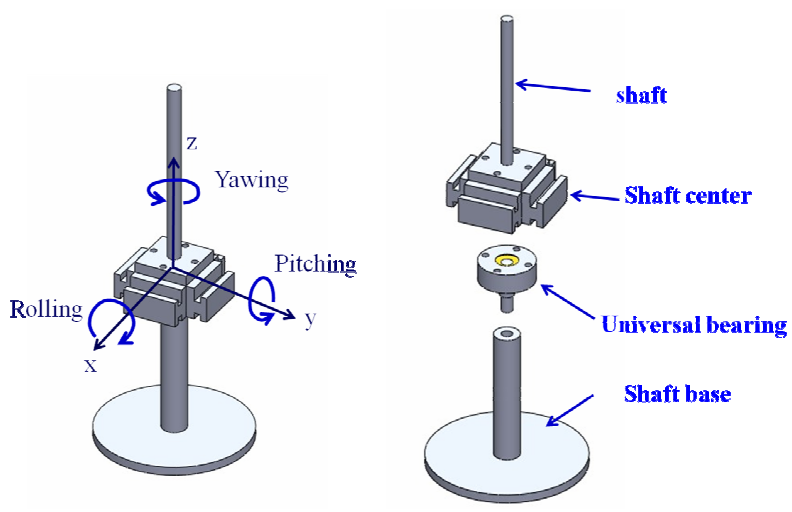

Fig. 4. Structure of the 3DOF shaft.

\section{Operating principle of the double excited 3DOF motor}

The operating principle of the proposed 3DOF motor is identical to the motion of the stepping motor, and the stepping motor rotates by one step via electric current switching. Consequently, the 3DOF motor determines its three directional rotations according to the exciting methods applied to the stator and rotor coils.

\subsection{Principles of rolling and pitching motions}

Given that the structures and the operating principle of the rolling and pitching poles are the same, only the principle of rolling motion is described in this study. The rolling motion rotates to the switching on the phase of the rolling pole in the excited state of the stator phase facing the rolling pole. Fig. 5 displays the $1 / 2$ cross sectional diagram of the $\mathrm{YZ}$ plane presenting the rolling motion. The rolling pole directly faces the $\mathrm{U}$ phase of the stator, and this 
phase is switched on. In Fig. 5(a), roll angle $\alpha$ is $0^{\circ}$, and the $B_{r}$ and $D_{r}$ phases are switched on. If we keep $B_{r}$ switched on, switch $\mathrm{D}_{\mathrm{r}}$ off, and switch $\mathrm{C}_{\mathrm{r}}$ on, the magnetic flux changes [Fig. 5(b)]. Torque occurs in the direction where the length of the rolling pole magnetic flux shortens, and it rotates by $10^{\circ}$, similar to what is shown in Fig. 5(c).

The rolling and pitching entail three steps, and a $\pm 30^{\circ}$ rotation is possible at $10^{\circ}$ intervals. Fig. 5 corresponds to the first step. In the other two steps, each pole rotates in accordance with the same principle. The exciting method of the phase on each pole at each step is shown in Table 1.
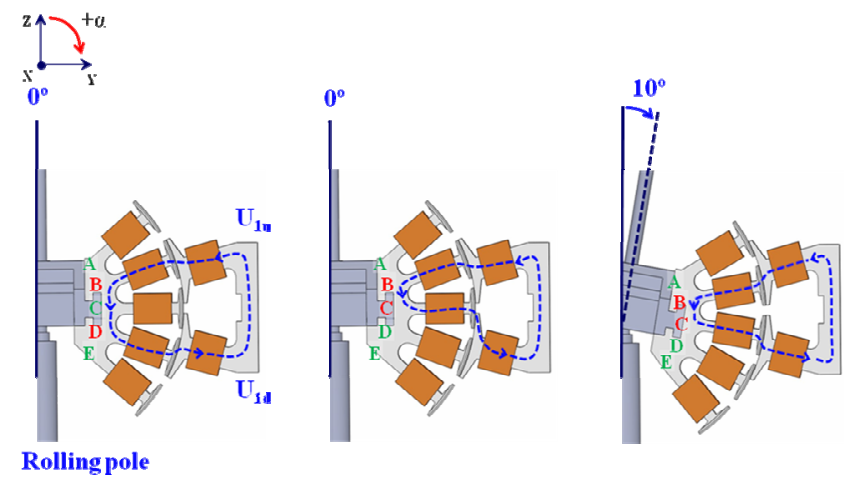

Fig. 5. Principle of rolling motion: (a) $B_{r}$ and $D_{r}$ excited; (b) $\mathrm{B}_{\mathrm{r}}$ and $\mathrm{C}_{\mathrm{r}}$ excited (unbalanced); (c) $\mathrm{B}_{\mathrm{r}}$ and $\mathrm{C}_{\mathrm{r}}$ excited (balanced).

Table 1. Position of the rotor depending on the excition phase

\begin{tabular}{c|c|c|c}
\hline & Step & $\alpha$ (degrees) & Excitation phase \\
\hline \multirow{4}{*}{$\begin{array}{c}\text { Rolling } \\
\text { or } \\
\text { pitching }\end{array}$} & $3^{\prime}$ & -30 & D, E \\
\cline { 2 - 4 } & $2^{\prime}$ & -20 & $\mathrm{C}, \mathrm{E}$ \\
\cline { 2 - 4 } & $\mathbf{1}^{\prime}$ & -10 & $\mathrm{C}, \mathrm{D}$ \\
\cline { 2 - 4 } & Initial & 0 & $\mathrm{~B}, \mathrm{D}$ \\
\cline { 2 - 4 } & 1 & 10 & $\mathbf{B}, \mathrm{C}$ \\
\cline { 2 - 4 } & 2 & 20 & $\mathrm{~A}, \mathbf{C}$ \\
\hline
\end{tabular}

Bold type: Negative current direction

\subsection{Principle of yawing motion}

Yawing motion occurs when the rotor rotates depending on the switching on the stator coils when the rolling and pitching poles are excited. Fig. 6 shows the top view of the proposed 3DOF motor and the yawing motion principle. The switches on B and D are on, both in the rolling and pitching poles of the rotor [Fig. 5(a)]. In Fig. 6(a), the rotor is facing stator $U$ (switched on) and yaw angle $\gamma$ is $0^{\circ}$. If the switch on $\mathrm{U}$ is off and that on $\mathrm{V}$ is on, the flow of magnetic flux is altered [Fig. 6(b)].

The rotor has torque occurring in the direction where the length of magnetic flux shortens, similar to what is shown in Fig. 6(c); the rotor rotates by $30^{\circ}$. The motion of the rotor involves 12 steps, and a $360^{\circ}$ rotation is possible. Fig. 6 corresponds to the first step, and the motion principles at each step are identical.

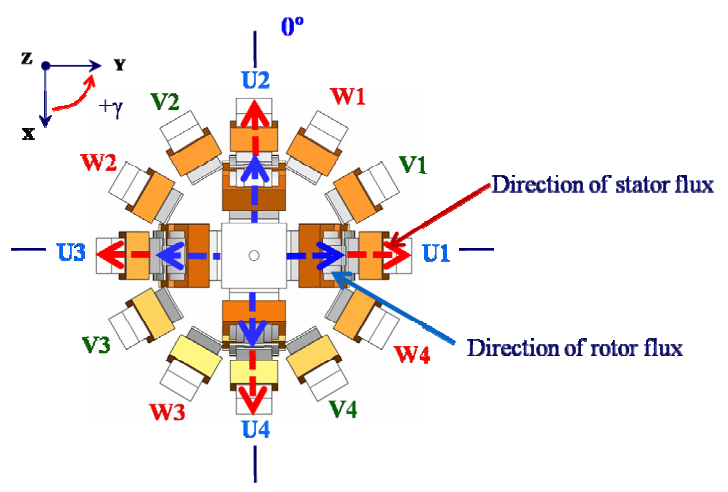

(a)

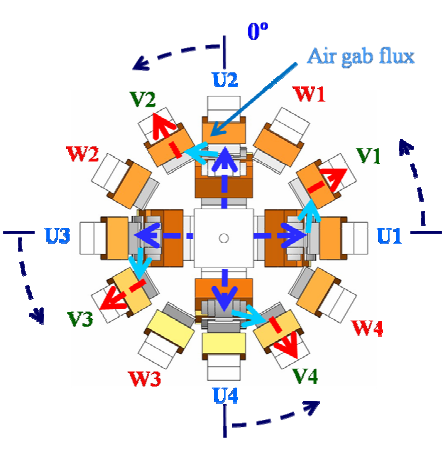

(b)

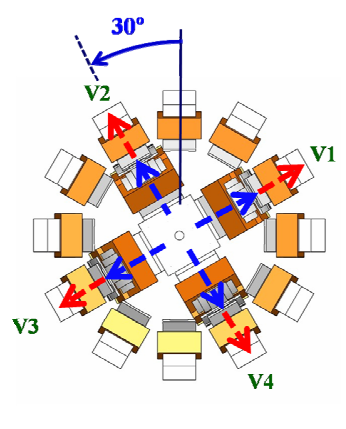

(c)
Fig. 6. Principle of yawing: (a) U phase excited; (b) V phase excited (unbalanced); (c) V phase excited (balanced).

\section{Design of the double excited 3DOF motor}

The flowchart of the design process for the proposed 3DOF motor is shown in Fig. 7, and the design dimensions are provided in Table 2. For design purposes, the range of rolling and pitching is set up to $30^{\circ}$, and a rotation of up to $30^{\circ}$ at a step angle of $10^{\circ}$ and step number of 3 are established. Once the step number and step angle are determined, the tooth widths of the stator and rotor can then be ascertained. By setting the loading ratio, the internal diameter, air gap, and outer diameter of the rotor are calculated. In addition, the laminated length is calculated counting the magnetic densities of the stator and rotor. Next, the turn number of the winding process is obtained by calculating the air gap magnetic flux for each pole, and the slot area is calculated by considering the obtained turn number. After all the values are obtained, determining whether the electric current density does not exceed the permitted value $(5.5 \mathrm{~A} / \mathrm{mm} 2)$ is necessary. If the 
electric current density does not exceed the permitted value, the static torque is analyzed using FE analysis, as explained in the succeeding section. The process is repeated until the analysis result satisfies the required torque. The designed motor is shown in Table 3.

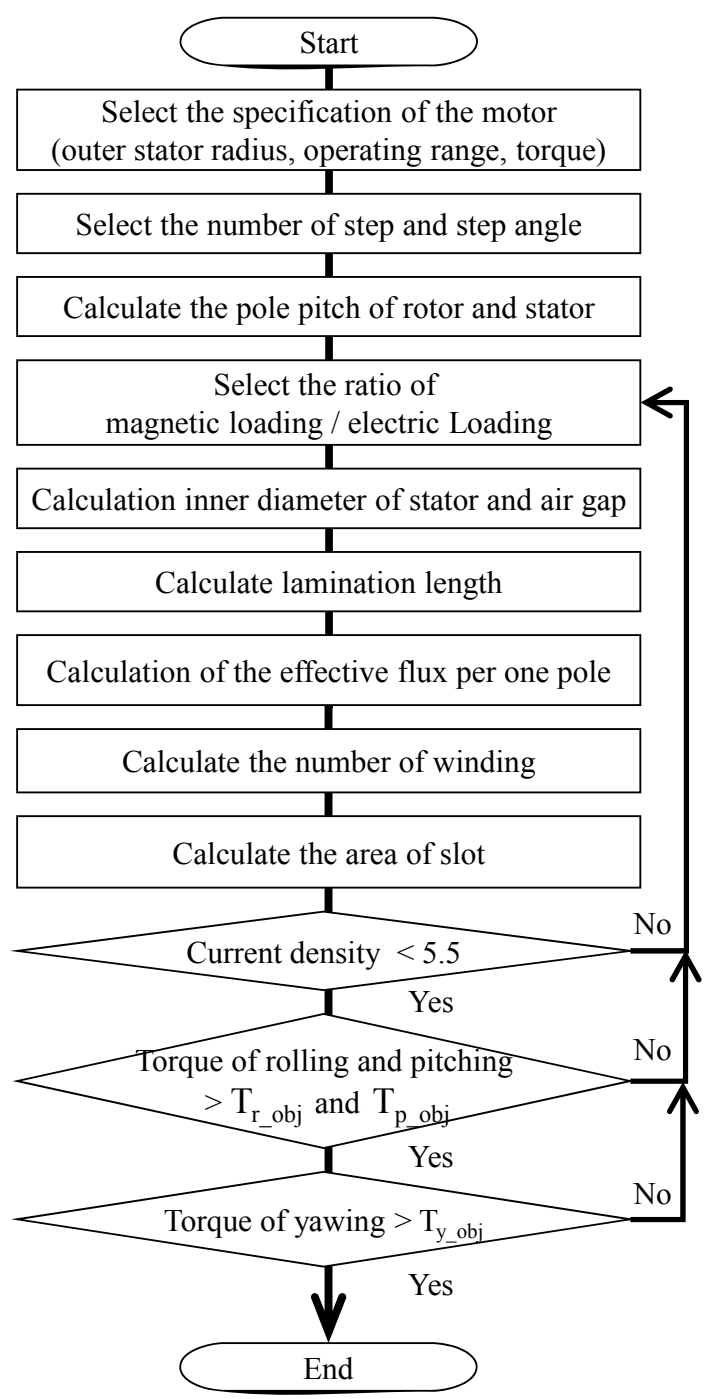

Fig. 7. Flowchart of the design.

Table 2. Design dimension

\begin{tabular}{|c|c|c|c|}
\hline Category & Direction & Unit & Design goal \\
\hline Torque $\mathrm{T}_{\mathrm{r}_{-} \mathrm{obj}}$ & Rolling & $\mathrm{Nm}$ & Average above 0.12 \\
\hline Torque $\mathrm{T}_{\mathrm{p}_{-} \text {obj }}$ & Pitching & $\mathrm{Nm}$ & Average above 0.12 \\
\hline Torque $\mathrm{T}_{\mathrm{y}_{-} \text {obj }}$ & Yawing & $\mathrm{Nm}$ & Average above 0.5 \\
\hline $\begin{array}{c}\text { Rotation range } \\
\mathrm{R}_{\mathrm{r} \_ \text {obj }}\end{array}$ & Rolling & degrees & \pm above 30 \\
\hline $\begin{array}{c}\text { Rotation range } \\
\mathrm{R}_{\mathrm{p}_{-} \text {obj }} \\
\end{array}$ & Pitching & degrees & \pm above 30 \\
\hline Rotation range $\mathrm{R}_{\mathrm{y}_{-} \text {obj }}$ & Yawing & degrees & \pm above 180 \\
\hline $\begin{array}{l}\text { Total outer } \\
\text { diameter }\end{array}$ & - & $\mathrm{mm}$ & Within $ø 160$ \\
\hline
\end{tabular}

Table 3. Specifications of the double excited 3DOF

\begin{tabular}{c|c}
\hline Stator & Øout $=80[\mathrm{~mm}]$, Øin $=53[\mathrm{~mm}]$ \\
\hline Radius & S18 \\
\hline Material & $13[\mathrm{~mm}]$ \\
\hline Stack width & $\begin{array}{c}\text { Number of turns, } 85 \\
\text { Coil diameter: } 0.8[\mathrm{~mm}]\end{array}$ \\
\hline Winding & Øout $=52.6[\mathrm{~mm}]$ \\
\hline Rotor & S18 \\
\hline Radius & $17[\mathrm{~mm}]$ \\
\hline Material & Number of turns, 65 \\
Stack width & Coil diameter: $0.8[\mathrm{~mm}]$ \\
\hline Winding &
\end{tabular}

\section{Analysis of static torque by 3D FEM}

To use the 3DOF motor like a robot joint, we need a torque to maintain the rotor in any random region, and this torque is called the holding torque. The characteristics of this torque are analyzed by 3D FEM.

\subsection{Static torque of rolling and pitching}

Because the static characteristics of rolling and pitching are identical, we describe only the attributes of rolling. Rolling, as explained in Section 3.1, moves at a total of three steps, and torque is analyzed at each stage. The conditions of analysis are as follows [Fig. 5(a)]: each rotor pole faces the stator $U$ phases, and the stator $U$ phase is excited.

In the first step (as indicated in Table 1), after the stator $\mathrm{U}$ phases, as well as the rotor $\mathrm{B}_{\mathrm{r}}$ and $\mathrm{C}_{\mathrm{r}}$ phases are excited, torque is analyzed by rotating roll angle $\alpha$ from $0^{\circ}$ to $20^{\circ}$. In the second step, after rotor $A_{r}$ and $C_{r}$ phases are excited, torque is analyzed using $\alpha$ from $10^{\circ}$ to $30^{\circ}$. In the last step, after rotor $A_{r}$ and $B_{r}$ phases are excited, torque is analyzed using $\alpha$ from $20^{\circ}$ to $30^{\circ}$. The designed motor is structurally capable of a rotation of only up to $30^{\circ}$ in the rolling and pitching directions. Thus, we analyze rotation up to $30^{\circ}$. The torque in the third step is smaller than that in the other steps because the three-dimensional magnetic flux leakage increases when rotation goes beyond $20^{\circ}$.

3D FEM analysis is conducted for each step, and the results are shown in Fig. 8. The average torque is about $0.13 \mathrm{Nm}$. The 3D FEM analysis results show that the proposed 3DOF motor can generate a holding torque in all the steps. Furthermore, the findings show that the torque converges to zero in each designed position.

\subsection{Static torque of yawing}

The torque for each yaw angle $\gamma$ is affected by roll angle $\alpha$ and pitch angle $\beta$. Because the torque characteristics are identical for each roll angle $\alpha$ and pitch 


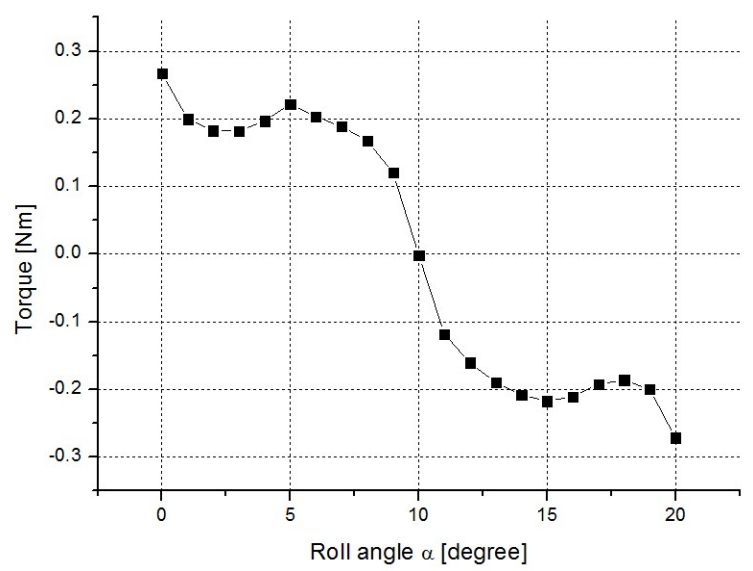

(a)

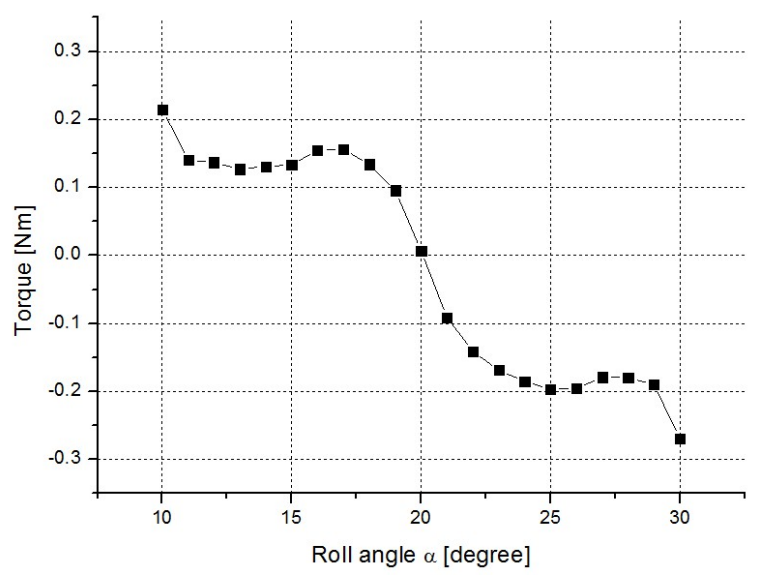

(b)

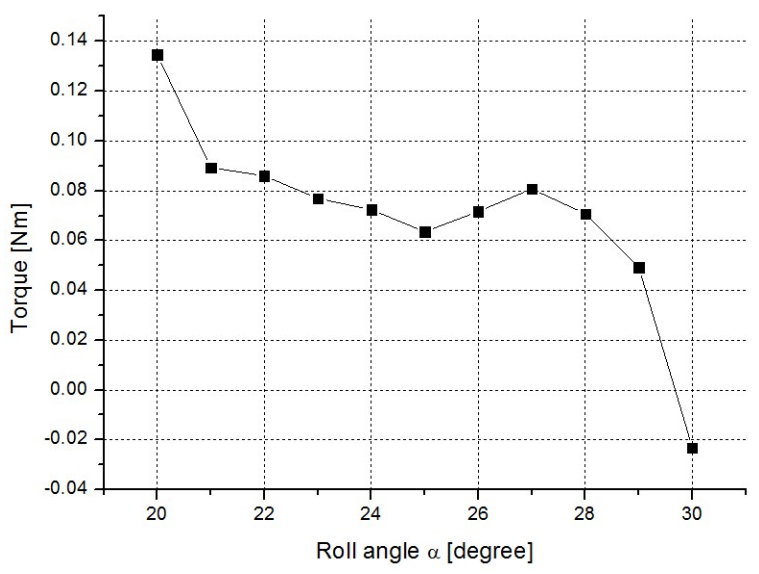

(c)

Fig. 8. Results of rolling simulation by 3D FEM: (a) Simulation results at the 1st step; (b) Simulation results at the 2nd step; (c) Simulation results at the 3rd step.

angle $\beta$, the torque properties for the yaw angle are analyzed for the roll angle $\alpha$ values of $0^{\circ}, 10^{\circ}, 20^{\circ}$, and $30^{\circ}$. First, if the rotor and stator are placed as in Fig. 6(a), the pitch angle is $0^{\circ}$ at excited $B_{p}$ and $D_{p}$ phases; stator $V$ is switched on. Then, the torque is analyzed using 3D FEM and rotating yaw angle $\gamma$ from $0^{\circ}$ to $30^{\circ}$. Second, the torque is examined by rotating yaw angle $\gamma$ from $0^{\circ}$ to $30^{\circ}$ when roll angle $\alpha$ is $10^{\circ}$, and the $B_{r}$ and $C_{r}$ phases are switched on. Third, the torque is studied by rotating yaw angle $\gamma$ from $0^{\circ}$ to $30^{\circ}$ when roll angle $\alpha$ is $20^{\circ}$, and the $\mathrm{A}_{\mathrm{r}}$ and $\mathrm{C}_{\mathrm{r}}$ phases are switched on. Finally, the torque is analyzed by rotating yaw angle $\gamma$ from $0^{\circ}$ to $30^{\circ}$ when roll angle $\alpha$ is $30^{\circ}$, and the $\mathrm{A}_{\mathrm{r}}$ and $\mathrm{B}_{\mathrm{r}}$ phases are switched on. Moreover, the generated torques on the $\mathrm{X}$ - and $\mathrm{Y}$-axis are analyzed under the same conditions.

The analysis results are shown in Fig. 9. The cogging torque of the yawing direction, which is obtained only by the excited rotor, is shown in Fig. 9(a). The average torque is about $1.0 \mathrm{Nm}$ [Fig. 9(b)]. As roll angle $\alpha$ increases, the rotor declines and the pitching pole air gap increases; thus, the maximal torque gradually decreases. Fig. 9(c) and (d) show the analysis results for the $\mathrm{X}$ - and Y-axis. As roll angle $\alpha$ increases, the torques also increase. These torque components affect the vibration of the shaft while the motor rotates in the yaw direction. Therefore, these torques require reduction by control or optimization.

\section{Prototype and experiments of the 3DOF motor}

A designed 3DOF motor is built (Fig. 10), with specifications listed in Table 4. The experimental method for the 3DOF motor differs from that of other existing motors on account of its rolling and pitching motions. Therefore, the test bed, which can convert a rotational axis, is built (Fig. 11). Fig. 12(a) shows the measurement system of the rolling torque using the test bed. The rolling motions are transferred to the rotational axis by the test bed. The rotations of the shaft from the rolling motions are measured by a coupling torque meter. The experiments on the rolling motion are performed under the same simulation conditions.

Fig. 12(b) shows the measurement system of the yawing torque. The experiment on the yawing motion is also performed under the same simulation conditions.

Table 4. Specifications of the prototype 3DOF motor

\begin{tabular}{c|c}
\hline \multicolumn{2}{c}{ Stator } \\
\hline Radius & Øout: $83[\mathrm{~mm}]$, Øin: $53[\mathrm{~mm}]$ \\
\hline Material & S 18 \\
\hline Stack width & Number of turns, Ns: $85[\mathrm{turn}]$ \\
Winding & Coil diameter: $0.8[\mathrm{~mm}]$ \\
\hline \multicolumn{2}{c}{ Rotor } \\
\hline Radius & Øout: $52.6[\mathrm{~mm}]$ \\
\hline Material & S 18 \\
\hline Stack width & $17[\mathrm{~mm}]$ \\
\hline \multirow{2}{*}{ Winding } & Number of turns, Nr: $65[\mathrm{turn}]$ \\
& Coil diameter: $0.8[\mathrm{~mm}]$ \\
\hline
\end{tabular}




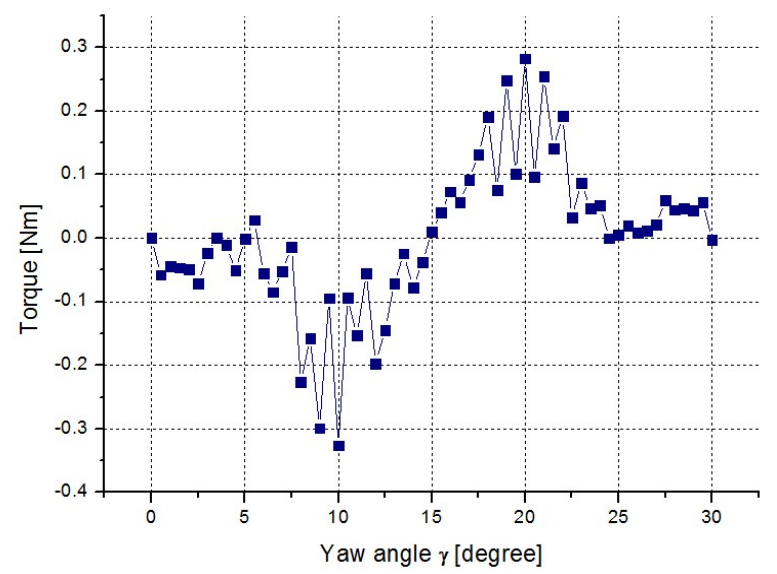

(a)

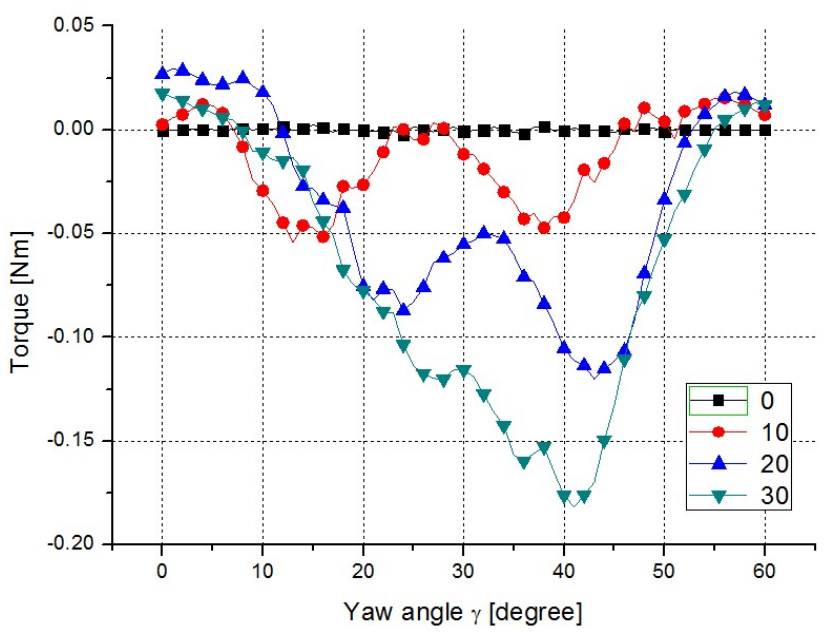

(c)

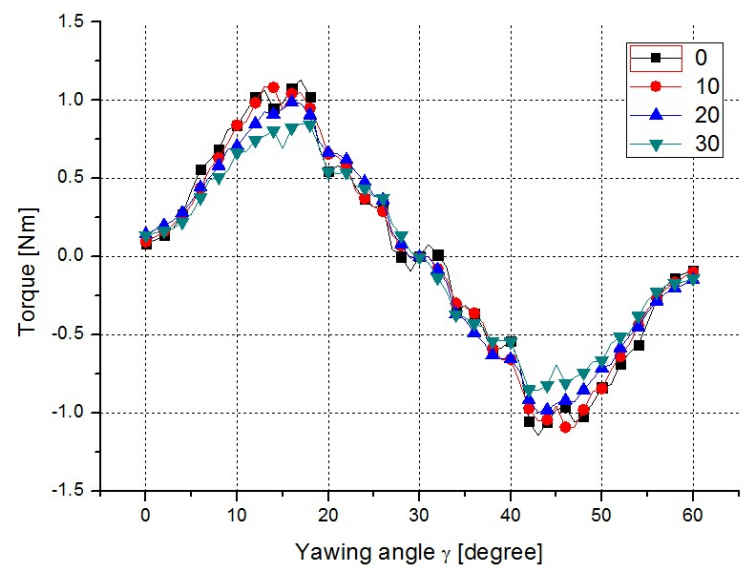

(b)

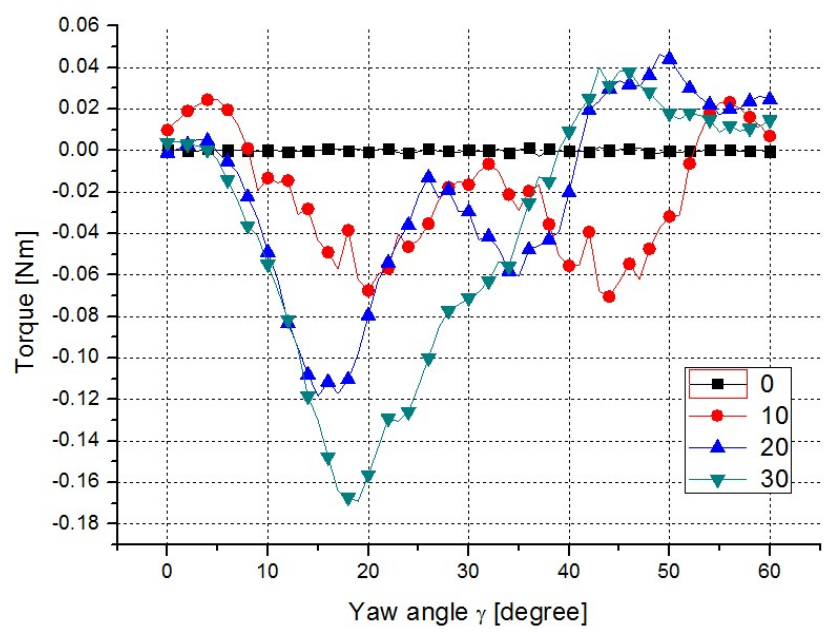

(d)

Fig. 9. Results of yawing simulation by 3D-FEM: (a) static torque on the Z-axis; (b) cogging torque wave form; (c) static torque on the $\mathrm{X}$-axis; (d) static torque on the Y-axis.

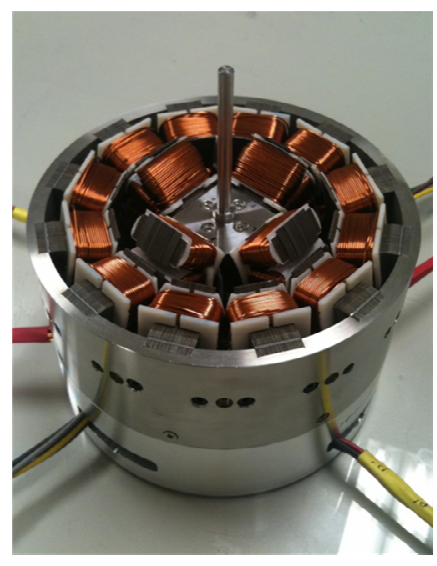

(a)

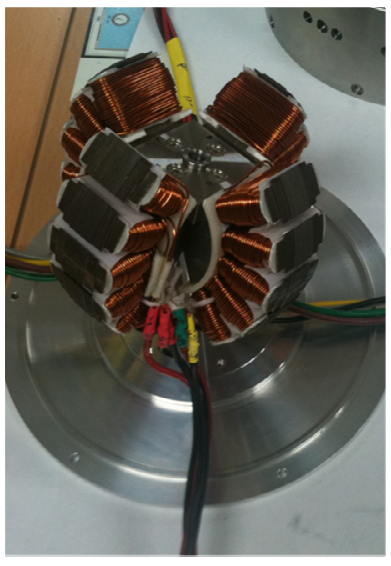

(b)

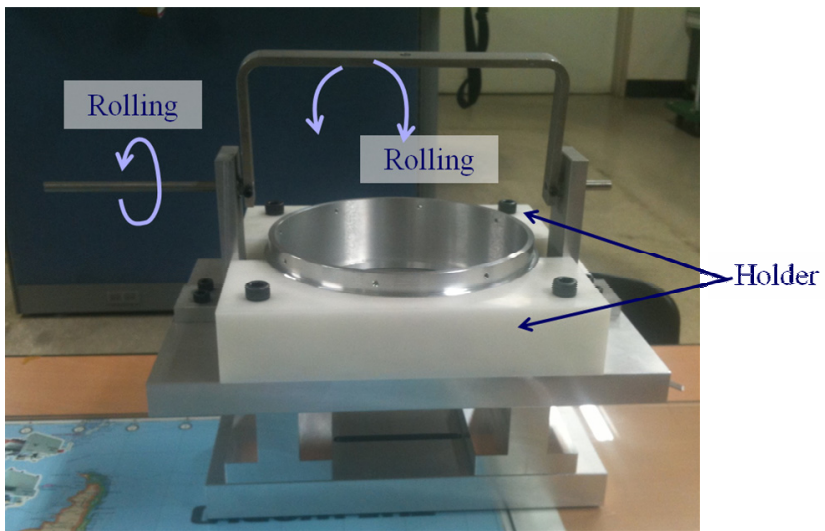

Fig. 11. Test bed for the measurement of the rolling torque.

Fig. 10. Prototype of the 3DOF motor: (a) structure of the 3DOF motor; (b) detailed rotor structure. 


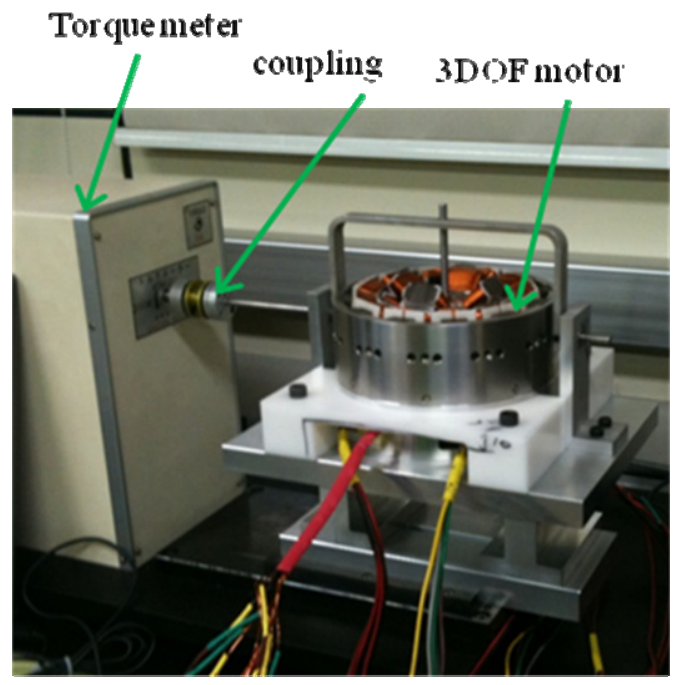

(a)

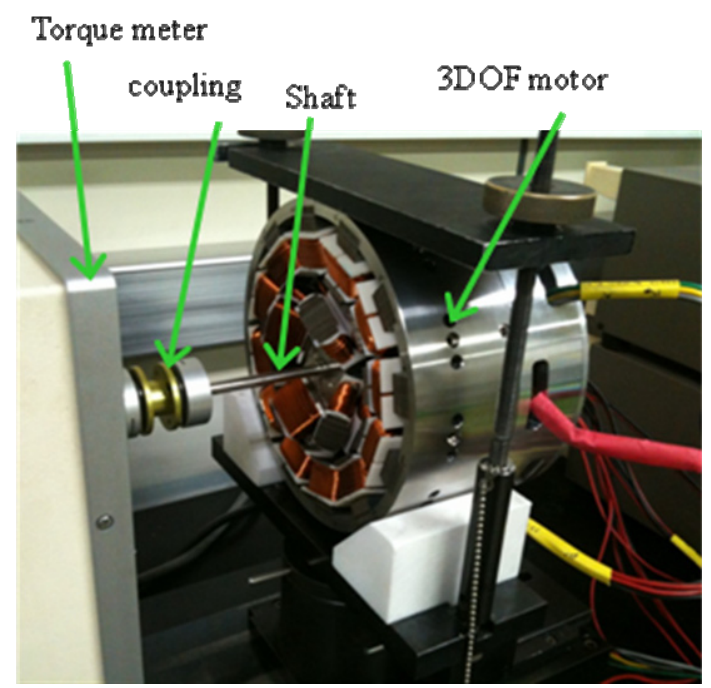

(b)

Fig. 12. Measurement system of the 3DOF motor: (a) rolling torque; (b) yawing torque.

Fig. 13(a), (b), and (c) show the comparison of the simulation and experimental results for rolling torque, while Fig. 13(d) shows the comparison of the simulation and experimental results for yawing torque. The yawing direction is analyzed at 1.3 Ampere because of the limitation in the measuring range of the torque meter. The average torque is about $0.13 \mathrm{Nm}$ in the rolling motion and about $0.7 \mathrm{Nm}$ in the yawing motion. The rolling motion entails three steps, and each step has a position where the torque becomes zero. These positions are the holding points of the rotor at each step. The experimental results show that torque becomes zero at the designed position.

The comparison between the simulations and experiments show that the deviations increase after the $20^{\circ}$ rotation of the third step in the yawing motion. These deviations occur because of frictions in the shaft.

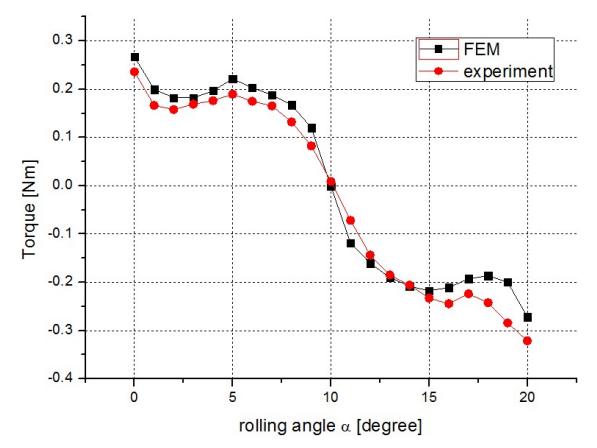

(a)

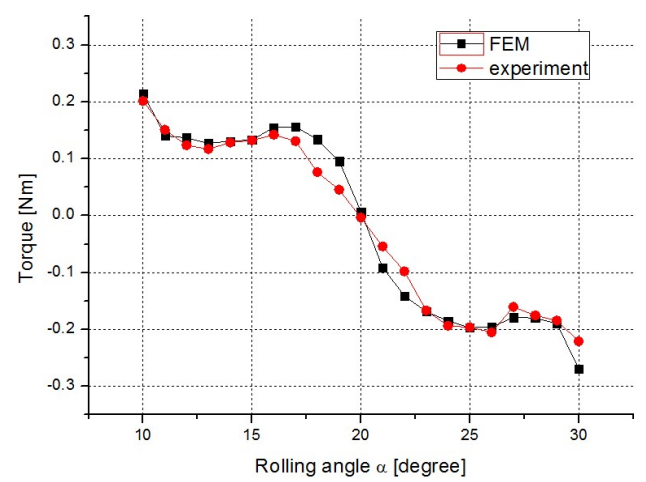

(b)

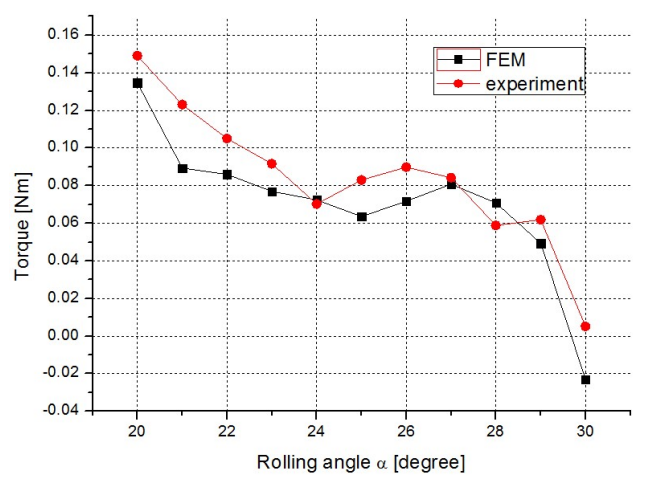

(c)

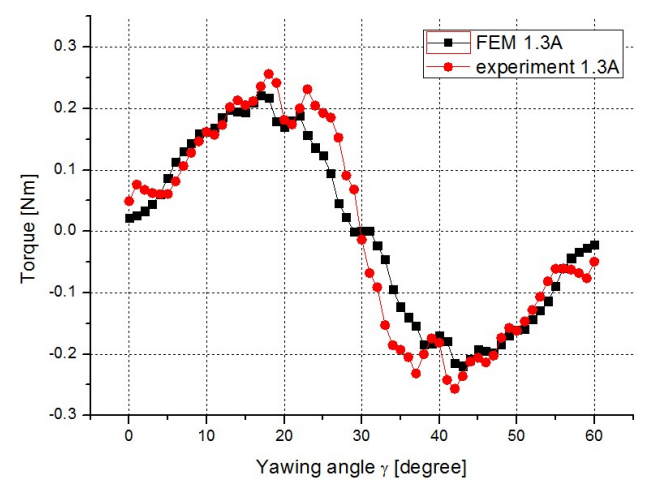

(d)

Fig. 13. Simulation and experimental results for the $3 \mathrm{DOF}$ motor: (a) 1st step of rolling; (b) 2nd step of rolling; (c) 3rd step of rolling; (d) yawing. 


\section{Conclusion}

In this paper, we have proposed a new laminatedstructure double excited 3DOF motor. The proposed motor is relatively easy to manufacture. We also elucidated the operating principles and design of the motor. The analysis of the static characteristics was performed by 3D FEM. To verify the simulation results and the effectiveness of the proposed structure, a prototype was fabricated. The simulation and experimental results were then compared.

In addition, by verifying that the holding torque occurs in every motion, we confirm the possibility of applying the proposed $3 \mathrm{DOF}$ motor to structures that require $3 \mathrm{DOF}$ motions, such as robot joints.

\section{Acknowledgment}

This research was supported by the WCU (World Class University) program through the National Research Foundation of Korea funded by the Ministry of Education, Science, and Technology (R33-2008-000-10104-0).

This work has been supported by KESRI (200900T100100558), which is funded by MKE(Ministry of Knowledge Economy)

\section{References}

[1] K. M. Lee, G. Vachtsevanos, C. K. Kwan, "Development of a Spherical Stepper Wrist Motor", Robotics and Automation, Proceedings, 1988 IEEE International Conference on 24-29, vol.1, pp 267-272, April 1988

[2] J. Wang, K. Mitchell, G. W. Jewell, D. Howe, "MultiDegree-of-Freedom Spherical Permanent Magnet Motors", Robotics and Automation, 2001 Proceedings 2001 Icra. IEEE intenational Conference on Volume 2, 1798-1805, 2001

[3] Y. Kaneko, I. Yamada, and K. Itao, "A spherical DC Servo Motor with 3DOF", Trans. ASME Dynam. Syst. Meas. Contr., vol. 111, no. 3, pp. 398-402, Sep. 1989

[4] K. Davey, G. Vachtsevanos, and R. Powers, "An Analysis of Fields and Torques in Spherical Induction motors", IEEE Transactions on Magnetics, vol. 23, no. 1, pp 273-282, Jan 1987

[5] K. M. Lee and C. K. Kwan, "Design Concept Development of a Spherical Stepper for Robotic Applications", IEEE Transactions on Robotics and Automation., vol. 7, no. 1, pp. 175-181, Feb. 1991

[6] K. Daveyr, G. Vachtsevanos, and R. Powers, "The Analysis of Fields and Torques in Spherical Induction Motors", IEEE Transactions on Magnetics, vol. 23, no. 1, pp. 273-282, Jan. 1987.

[7] Foggia. A, Olivier. E, Chappuis. F, Sabonnadiere. J.C "A New Three-Degrees-of-Freedom Electromagnetic Actuator", in IEEE Industry Application Society Annual Meeting, pp. 137-141, 1998
[8] B. Dehez, G. Galary, D. Grenier, and B. Raucent, "Development of a Spherical Induction Motor With Two Degrees of Freedom", IEEE Tran Magn., vol. 42, no 8, pp. 2077-2089, August 2006.

[9] Dong- Chul. Lee, B. I. Kwon, "A Novel Structured 3DOF Spherical Motor" ICEMS2006, Nagasaki, Japan, 20 - 23, November 2006

[10] Jae-sung Lee, Dae-kyoung Kim, Soo-whang Baek, Se-hyun Rhyu, Byung-il Kwon, "Newly Structured Double Excited Two-Degree-of-Freedom Motor for Security Camera", IEEE Transaction on Magnetics, Vol. 44, pp. 4041-4044, Nov. 2008

[11] J. B. Wang, W. Y. Wang, and W. Geraint, "A Novel Spherical Permanent Actuator with Three Degreesof-Freedom", IEEE Transactions on Magnetic, vol. 34, no. 4, pp. 2078-2080, Jul. 1998.

[12] Gregory S. Chirikjian, and David Stein, "Kinematic Design and Commutation of a Spherical Stepper Motor", IEEE/ASME Transaction on Mechatronics, vol. 4, no 4, pp. 342-353, December 1999

[13] W. Wang, J. Wang, G. W. Jewell, and D. Howe, "Design and Control of a Novel Spherical Permanent Magnet Actuator with Three Degrees of Freedom", IEEE/ASME Transaction on Mechatronics, vol 8, no 4, December 2003

[14] Liang Yan, I. Ming Chen, et al., "Design and analysis of a permanent magnet spherical actuator", IEEE/ASME Transaction on Mechatronics, vol. 13, no. 2, pp. 239-248, April 2008

[15] Changliang Xia, Hongfeng Li, and Tingna Shi, "3-D Magnetic Field and Torque Analysis of a novel Halbach Array Permanent-Magnet Spherical Motor" IEEE Transactions on magnetic, vol. 44, no. 8, pp. 2016-2020, August 2008

[16] Changliang Xia, Peng Song, Hongfeng Li, Bin Li, and Tingna Shi, "Research on Torque Calculation Method of Permanent-Magnet Spherical Motor Based on the Finite-Element Method", IEEE Transactions on Magnetics, vol. 45, no. 4, pp. 2015-2022, April 2009

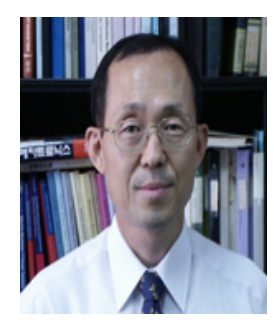

Byung-il Kwon received his BS and MS degrees in Electrical Engineering from Hanyang University, Korea, and his $\mathrm{PhD}$ degree in Electrical Engineering from Tokyo University, Japan. He is currently a Professor at Hanyang University. His research interests are linear drive systems, numerical analysis of machines, and motor control.

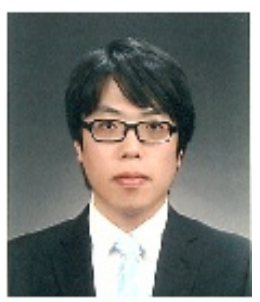

Young-boong Kim received his BS degree in Electronic Information System Engineering from Hanyang University, Korea. His research interests are electric machines. 